\title{
Raised serum soluble interleukin-2 receptor concentrations in cystic fibrosis patients with and without evidence of lung disease
}

\author{
Elif Dagli, Jill A Warner, C R Besley, J O Warner
}

\begin{abstract}
Soluble interleukin-2 receptor (sIL-2R-CD25) concentrations were measured in the sera of 115 children with cystic fibrosis and 45 aged matched controls. Above the age of 4 years children with cystic fibrosis had significantly raised concentrations irrespective of disease status as judged by Shwachman score, lung function, or evidence of pseudomonas colonisation. It is believed that these data indicate that $\mathbf{T}$ lymphocyte activation can be detected before there is clinical evidence of lung inflammation due to infection in cystic fibrosis. They support the notion that early use of anti-inflammatory (immunosuppressive) drugs may have a role in delaying the progress of lung damage in cystic fibrosis.
\end{abstract}

There is increasing evidence that immune mediated inflammation is at least partly responsible for progressive lung damage in cystic fibrosis. Immune complexes wtih Pseudomonas aeruginosa antigen and autoantibodies found in the serum, sputum, and the tissues, high levels of elastin cleavage products in urine, and elastolysis in lungs all correlate with disease severity. These findings provide strong evidence that immunologically mediated tissue injury occurs in patients with cystic fibrosis and advanced lung disease. ${ }^{1-4}$

Continuous antigenic stimulation can have two consequences in cystic fibrosis, one being temporary immune unresponsiveness, and the other being a chronic hypersensitivity reaction or excessive immune response. ${ }^{5}$ This excessive response is reflected in the form of high concentrations of serum immunoglobulins, neutrophil elastase, immune complexes, and a high incidence of detectable autoantibodies. ${ }^{1-5}$ All of these abnormalities are seen in patients with severe lung disease long after the clinical and lung function findings indicate the presence of lung involvement. However it is known that inflammation and mild obstructive ventilatory defects occur early, before heavy lung infection is obvious. ${ }^{15}$ For this reason we wished to identify a more sensitive marker of this early inflammation which could be used to assess progress and the severity of disease.

As $\mathrm{T}$ lymphocytes have a central role in the orchestration of immune responses, we decided to investigate one index of $T$ cell activation. Interleukin-2 (IL-2) known as $\mathrm{T}$ cell growth factor induces the proliferation of not only the $T$ cells but also lymphokine activated killer cells. It also has the effect of enhancing natural killer activity. ${ }^{6-14}$ IL-2 induces the expression of its own receptor. This receptor is expressed on several mononuclear cells including $T$ cells. Human peripheral blood mononuclear cells when activated in vitro were shown to release a soluble form of IL-2 receptor (sIL-2R) into the tissue culture supernatants, and in this form it may have an immunoregulatory function. ${ }^{9}$ This sIL-2R is the part of the receptor shed into the circulation, which lacks the transmembrane and cytoplasmic portion. ${ }^{6-13}$ There are detected concentrations in the serum of normal individuals, and raised concentrations have been found in autoimmune disease, transplant rejection, acute eczema, lymphoma, and leukaemia relapses. ${ }^{15-17}$

We have therefore investigated the sIL-2R concentrations in patients with cystic fibrosis with regard to their clinical findings to show the relationship of $T$ cell activation to the outcome of the disease.

\section{Patients and methods}

A total of 177 blood samples were obtained from 115 patients with cystic fibrosis during their yearly assessments. On the same day chest radiographs and (where possible) lung function tests were performed. The presence of pseudomonas colonisation and acute infection was noted with simultaneous clinical evaluation of the patient by Shwachman score. ${ }^{18}$ The scoring was done by two clinicians independently and the average of the two scores recorded. Diagnosis of acute infection was based on the clinical findings in addition to raised white cell count and $\mathrm{C}$ reactive protein concentrations. The blood samples were analysed for serum sIL-2R, IgA, IgG, IgM, and IgE concentrations. Serum sIL-2R concentrations were studied using a sandwich enzyme immunoassay cell-free soluble IL-2 receptor kit (T Cell Sciences Inc). The method was applied according to the instructions of the manufacturer.

sIL-2R concentrations were correlated with (i) lung function parameters, (ii) total lung capacity by plethysmography minus that measured by helium dilution as a measure of gas trapping (TLC-VA), (iii) forced expiratory flow at $50 \%$ of vital capacity from a flow-volume loop (FEF 50\%) and forced vital capacity (FVC), (iv) serum immunoglobulins, and (v) Shwachman score. The effect of acute infection and presence of pseudomonas colonisation on sIL-2R concentrations were also assessed.

Control samples were obtained, with the consent of the parents, from 45 children attending the Paediatric Day Surgery Unit at Southampton General Hospital for routine 
Table 1 sIL-2R concentrations $(\mathrm{U} / \mathrm{ml})$ in controls and patients with cystic fibrosis with regard to acute infection and/or pseudomonas colonisation. Results are mean $(S D)$

\begin{tabular}{|c|c|c|c|c|c|c|}
\hline \multirow{2}{*}{$\begin{array}{l}\text { Age } \\
\text { groups } \\
\text { (years) }\end{array}$} & \multirow[t]{2}{*}{ Patients } & \multirow[t]{2}{*}{ Controls } & \multicolumn{2}{|l|}{ Acute infection } & \multicolumn{2}{|c|}{ Pseudomonas colonisation } \\
\hline & & & With & Without & With & Without \\
\hline $0-3.9$ & $\begin{array}{l}1105 \cdot 5(335 \cdot 1) \\
{[n=10]}\end{array}$ & $\begin{array}{l}851 \cdot 9(334 \cdot 3) \\
{[n=16]}\end{array}$ & $\begin{array}{l}1205 \cdot 0(360 \cdot 6) \\
{[n=2]}\end{array}$ & $\begin{array}{l}1080 \cdot 6(349 \cdot 7) \\
{[n=8]}\end{array}$ & $\begin{array}{l}1133 \cdot 3(335 \cdot 0) \\
{[n=3]}\end{array}$ & $\begin{array}{c}1093 \cdot 6(361 \cdot 2) \\
{[n=7]} \\
n=0 \cdot 65\end{array}$ \\
\hline $4-7 \cdot 9$ & $\underset{[n=40]}{828 \cdot 1(334 \cdot 5)^{p}}$ & $\begin{array}{l}068 \\
503 \cdot 9(91 \cdot 1) \\
{[n=9]} \\
0038\end{array}$ & $\begin{array}{l}816 \cdot 7(312 \cdot 5) \\
{[n=14]}\end{array}$ & $\begin{array}{l}903 \cdot 0(319 \cdot 6) \\
{[n=26]} \\
43\end{array}$ & \multirow{2}{*}{\multicolumn{2}{|c|}{$\begin{array}{cc} & p=0.65 \\
872.9(318 \cdot 1) & 876.8(321 \cdot 8) \\
{[n=19]} & {[n=21]} \\
& p=0.63 \\
753.9(209 \cdot 2) & 834.6(308 \cdot 4) \\
{[n=21]} & {[n=27]} \\
& p=0.63\end{array}$}} \\
\hline $8-11 \cdot 9$ & $\begin{array}{l}739 \cdot 9(263 \cdot 5) \\
{[n=48]}\end{array}$ & $\begin{array}{l}490 \cdot 0(78 \cdot 3) \\
{[n=10]} \\
\cdot 0005^{*}\end{array}$ & $\begin{array}{l}778 \cdot 6(228 \cdot 5)^{F} \\
{[n=12]}\end{array}$ & $\begin{array}{l}804 \cdot 9(284 \cdot 4) \\
{[n=36]}\end{array}$ & & \\
\hline$\geqslant 12$ & $\begin{array}{l}827 \cdot 9(337 \cdot 8) \\
{[n=79]}\end{array}$ & $\begin{array}{l}370 \cdot 0(138 \cdot 3) \\
{[n=10]} \\
\cdot 0005\end{array}$ & $\begin{array}{l}959 \cdot 6(350 \cdot 4) \\
{[n=33]}\end{array}$ & $\begin{array}{l}719 \cdot 7(292 \cdot 8) \\
{[n=46]} \\
0021^{*}\end{array}$ & $\begin{array}{l}806 \cdot 1 \\
{[n=46]}\end{array}$ & $\underset{p=0 \cdot 81}{[n=33]}$ \\
\hline
\end{tabular}

${ }^{*}$ Significant differences.

surgical procedures. The children did not have any history of asthma, eczema, hay fever, any known allergies, or recent infection. They all had normal concentrations of $\mathrm{C}$ reactive protein. The data on serum sIL-2R concentrations were analysed in four different age groups both in patients and controls. The age groups were separated as follows: group 1: 0-3.9 years, group $2: 4-7 \cdot 9$ years, group $3: 8-11 \cdot 9$ years, and group $4: \geqslant 12$ years.

Statistical analyses were done by minitab computer program using correlation analysis and Mann-Whitney test. The significance values were given in tables of relevant data.

\section{Results}

The mean (SD) sIL-2R concentrations of patients with cystic fibrosis was $840(320 \cdot 4)$ $\mathrm{U} / \mathrm{ml}$ with a median of $790.0 \mathrm{U} / \mathrm{ml}$. The breakdown of these data into age groups compared with controls are shown in table 1 and fig 1. There was no significant statistical difference between patients with cystic fibrosis and controls in the first age group. sIL-2R concentrations were significantly higher than controls in all groups after 4 years of age. Serum sIL-2R concentrations were not significantly different in patients with and without pseudomonas colonisation in all age groups. Similarly there were no differences in children under 12 years of age with and without acute infection. However, the patients with cystic fibrosis above

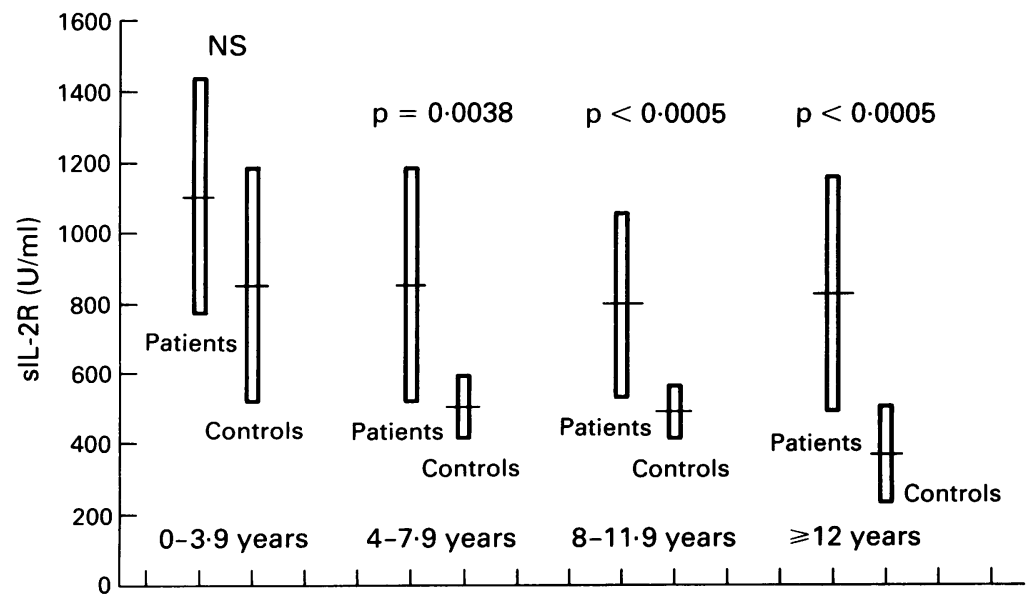

Figure I Comparisons of serum sIL-2R concentrations in patients with cystic fibrosis and age matched control children. Statistical analysis by Mann-Whitney test.

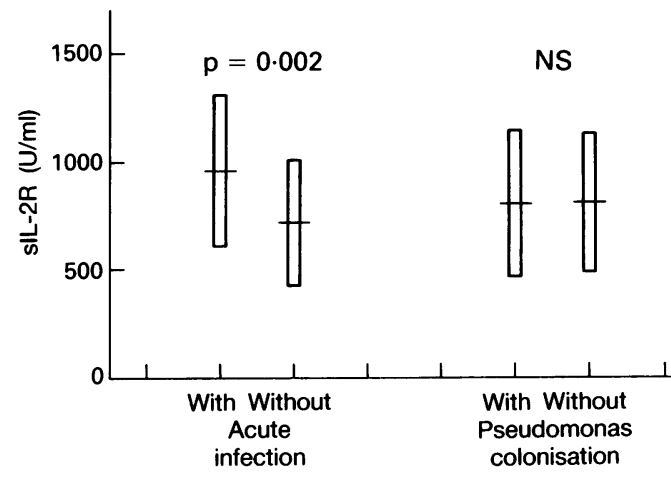

Figure 2 Comparison of serum sIL-2R concentrations in patients with cystic fibrosis above 12 years of age with and without acute infection and pseudomonas colonisation. Statistical analysis by Mann-Whitney test.

Table 2 Correlation of $s I L-2 R$ concentrations and various clinical parameters

\begin{tabular}{lc}
\hline & $r$ Value \\
\hline Shwachman score & -0.17 \\
TLC-VA & -0.019 \\
FVC & 0.151 \\
FEF 50\% & -0.097 \\
IgE & -0.121 \\
IgA & 0.048 \\
IgM & -0.019 \\
IgG & -0.032 \\
\hline
\end{tabular}

12 years of age with acute infection had significantly higher concentrations of sIL-2R than those without acute infection $(p=0.0021)$ as shown in table 1 and fig 2.

Shwachman scores and sIL-2R concentrations recorded simultaneously showed no correlation (correlation coefficient $\mathrm{r}=-0.16, \mathrm{p}>0.05$ ). In addition to this, sIL-2R concentrations showed no correlation between different parameters of lung function TLC-VA, FVC, FEF $50 \%$, and IgE, IgA, IgM, and IgG concentrations as shown in table 2 .

\section{Discussion}

In patients with cystic fibrosis many immunological abnormalities due to continuous antigenic stimulation of the immune system have been reported. ${ }^{1-5}$ Our findings of significantly raised concentrations of sIL-2R are new and are probably a reflection of sustained $T$ cell activation in these patients. As sIL-2R varies with age and is especially high in early childhood, 
perhaps due to the normally higher lymphocyte count, we analysed our data grouping the patients into different age groups. ${ }^{17}$ The sIL-2R concentrations only just failed to show a significant difference between patients and controls under the age of 4 years but the differences were highly significant in older children (table 1). These data provide yet more evidence of an excessive immune response in patients with cystic fibrosis.

Superficially it seems that the lack of correlation between sIL-2R and clinical scores and the presence of pseudomonas colonisation, lung function abnormality, or raised immunoglobulins, does not comply with the hypothesis of immunologic lung injury in cystic fibrosis. However, raised concentrations of sIL-2R may be the first indicator of a developing inflammatory process, which increases even more during acute infection. With time the chronic inflammation produces changes in other immunological indices further down the activation pathways, such as immunoglobulin increases, ${ }^{19}$ raised $C$ reactive protein concentrations, and the release of neutrophil granule products, ${ }^{20}$ which produce and therefore correlate with the increasing severity of disease.

sIL-2R is known to bind IL-2 efficiently competing with receptor on the cell surface and therefore may have a role in downregulating IL-2 dependent lymphocyte function. ${ }^{21}$ Moreover, the rapid increase in sIL-2R after cellular activation may reduce receptor density on the cell surface below the critical threshold level reducing further lymphocyte proliferation. Increased sIL-2R concentrations may be the first sign of airway colonisation and inflammation that will eventually lead to an excessive immune response and lung damage. Even if sIL-2R is part of a compensatory response it is inadequate to overcome the enormous stimulation produced by the massive antigenic load of organisms which are never completely cleared from the airway.

These data support the fairly recent therapeutic recommendation of the use of antiinflammatory drugs in cystic fibrosis. Steroids have been shown to delay deterioration even in young patients with cystic fibrosis but have not become part of routine protocols due to potential side effects. ${ }^{4}$ These preliminary cross sectional observations confirm the role of the host immune response even at an early stage in the development of lung damage in cystic fibrosis and suggest that the early use of non-steroidal antiinflammatory drugs may be important in the prevention of progression of disease. However longitudinal studies are now required to establish whether high concentrations of sIL-2R are associated with faster deterioration in lung function and whether therapeutic intervention has an effect on concentrations and clinical state.

Thanks to the Cystic Fibrosis Research Trust for financial support of the study.

1 Thomassen MJ, Demko CA, Doershuk CF. Cystic fibrosis: a review of pulmonary infections and interventions. Pediatr Pulmonol 1987;3:334-51.

2 Suter S, Schaad UB, Roux L, Nydegger UE, Waldvogel FA. Granulocyte neutral proteases and pseudomonas elastase as Granulocyte neutral proteas and pse fibrosis. $\mathcal{J}$ Infect Dis 1984;149:523-31.

3 Hoiby N Schiotz PO. Immune complex mediated tissue dama in the lungs of cystic fibrosis patients with chronic damage in the lungs of cystic fibrosis patients with chronic Pseudomonas aerugino

4 Auerbach HS, Williams M, Kirkpatrick JA, Colten HR. Alternate-day prednisone reduces morbidity and improves Alternate-day prednisone reduces morbidity and imp
function in cystic fibrosis. Lancet 1985;ii:686-8.

5 Doring G, Albus A, Hoiby N. Immunologic aspects of cystic Doring G, Albus A, Hoiby N. Immun
fibrosis. Chest 1988;94(suppl): 109.

6 Cantrell DA, Smith KA. The interleukin-2 T-cell system: a new cell growth model. Science 1984;224:1312-6.

7 Robb RJ, Greene WC, Rusk C. Low and high affinity cellular receptors for interleukin 2 . Implications for the level of Tac antigen. $\mathcal{f} \operatorname{Exp}$ Med 1984;160:1126-46.

8 Herrod HG, Interleukins in immunologic and allergic diseases. Ann Allergy 1989;63:269-72.

9 Rubin LA, Kurman CC, Fritz ME, et al. Soluble interleukin 2 receptors are released from activated human lymphoid cells in vitro. F Immunol 1985;135:3172-7.

10 Rocha B. Lembezat M, Freitas A, Bandeira A. Interleukin 2 receptor expression and interleukin 2 production in exponentially growing $\mathrm{T}$ cells: major differences between in vivo and in vitro proliferating $T$ lymphocytes. Eur $\mathcal{f}$ vivo and in vitro prolifer.

11 Herrmann T, Josimovic-Alasevic O, Mouzaki A, Diamantstein $T$. Demonstration of two distinct forms of released low T. Demonstration of two distinct forms of released low
affinity-type rat IL-2 receptors. Immunology 1989;66:

12 Smith KA. The interleukin receptor. Adv Immunol 1988;42: 165-79.

13 Mertelsmann R, Welte K. Human interleukin 2: molecular biology, physiology and clinical possibilities. Immunobiology 1986;172:400-19.

14 Phillips JH, Takeshita T, Sugamura K, Lanier LL. Activation of natural killer cells via the p75 interleukin-2 receptor. f Exp Med 1989;170:291-6.

15 Coles M, Rose M, Yacoub M. Appearance of cells bearing the interleukin-2 receptor in peripheral blood of cardiac transinterleutients and their correlation with rejection episodes. Transplant Proc 1987;19:2546-7.

16 Kapp A, Piskorski A, Schopf E. Elevated levels of interleukin 2 receptor in sera of patients with atopic dermatitis and 2 receptor in sera of patients with atopic

17 Komp DM, Shapiro E, McNamara J. Soluble interleukin-2 receptor in childhood non-Hodgkin's lymphoma. Blood receptor in child

18 Shwachman H, Kulczycki LL. Long term study of one hundred and five patients with cystic fibrosis. Am $\mathcal{F}$ Dis Child 1958;96:6-15.

19 Turner MW, Warner JO, Stokes CR, Normal AP. Immunological studies in cystic fibrosis. Arch Dis Child 1978;53: 631-8.

20 Rayner RJ, Wiseman MS, Gordon SM, Norman D, Hillier EJ, Shale DJ. Inflammatory markers in cystic fibrosis. Respir Med 1991;85:139-45.

21 Rubin LA, Jay G, Nelson DL. The released interleukin 2 receptor binds interleukin 2 efficiently. I Immunol 1986; 137:3841-4. 